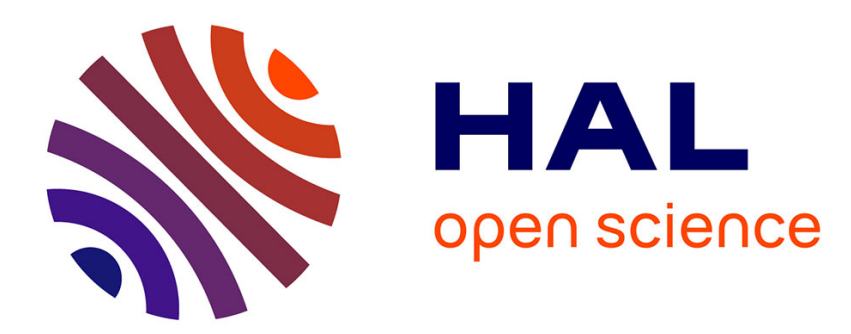

\title{
The Low Velocity Impact Behaviour of Glass-Polymer Laminated Plates
}

A. Ball

\section{To cite this version:}

A. Ball. The Low Velocity Impact Behaviour of Glass-Polymer Laminated Plates. Journal de Physique IV Proceedings, 1997, 07 (C3), pp.C3-921-C3-926. 10.1051/.jp4:19973155 . jpa-00255444

\section{HAL Id: jpa-00255444 https://hal.science/jpa-00255444}

Submitted on 1 Jan 1997

HAL is a multi-disciplinary open access archive for the deposit and dissemination of scientific research documents, whether they are published or not. The documents may come from teaching and research institutions in France or abroad, or from public or private research centers.
L'archive ouverte pluridisciplinaire HAL, est destinée au dépôt et à la diffusion de documents scientifiques de niveau recherche, publiés ou non, émanant des établissements d'enseignement et de recherche français ou étrangers, des laboratoires publics ou privés. 


\title{
The Low Velocity Impact Behaviour of Glass-Polymer Laminated Plates
}

\author{
A. Ball
}

\author{
University of Cape Town, Materials Engineering, Private Bag, Rondebosch, 7700 Cape Town, \\ Republic of South Africa
}

\begin{abstract}
Thin glass plates when impacted with by projectiles travelling at velocities up to $100 \mathrm{~ms}^{-1}$ may fracture as a consequence of front face contact or back face bending stresses. The relative magnitude of these stresses is dependent upon plate thickness. The design of composite laminate plates, which may incorporate front, rear or interply layers of polymeric material, is based on a need to reduce both the impact and bending stresses. The incorporation of toughened, hardened and surface treated glass plates also increases the effective toughness of the laminate.
\end{abstract}

\section{Introduction}

It is important that the fracture processes caused by projectile impact of transparent plates and laminates are understood since the integrity of security visors and screens for high speed vehicles, trains and aircraft is important. This paper considers the competing fracture processes due to impact stresses on the front surface and the bending stresses generated on the rear or back surface. Simple laminates consisting of glass and transparent polymeric materials have been tested with a view to assessing the inhibition of these fracture processes and ultimately with a view to the systematic design of laminated plates. Previous papers have considered the modes of fracture in monolithic glass plates of different thicknesses.[1], the phenomenon of Hertzian cracking[2] and the effects of surface treatments on the fracture behaviours. [3]

A significant effect of plate thickness is the ability of thin (less than $3 \mathrm{~mm}$ ) plates to resist the impact damage on the front face by bending. At low velocities, the thin plates remain undamaged whilst thicker plates showed Hertzian cracking.[1] At higher velocities, the thin plates showed both Hertzian cracks and cracking at the back surface due to bending. The optimum thickness for a given velocity of impact occurs when the probability of Hertzian damage is equal to the probability of cracking on the back surface. These probabilities are controlled not simply by the state of stress but also by the surface areas under stress and the defect size and density in these stressed areas. These conclusions are significant in the overall design of laminates; visors and screens. Hertzian cracking of the front surface can be resisted by allowing some bending; chemical or thermal strengthening the surface would inhibit the initiation and propagation of cracks from flaws. Furthermore, a thin but relatively tough coating could 'disperse' the Hertzian contact stress and inhibit the cone cracking.

The controlled bending of the front layer of a laminate can be achieved using an interlayer of a soft transparent polymer such as polyvinyl butyral. The thickness and elasticity of this layer can be chosen to allow an optimum degree of bending. This interlayer also has a protective effect on the second layer of glass by inhibiting Hertzian cracking at the interface. The rear plate should be of sufficient thickness to prevent overall bending of complete laminate and cracking from the back or rear surface. The experiments described herein have been carried out in order to verify some of these hypotheses. 


\section{Experimental}

A conventional airgun was used to propel $5 \mathrm{~mm}$ diameter 0,5 gram steel balls along a $1 \mathrm{~m}$ long barrel and impact on the specimen. The velocity of the projectile was determined by recording the time interval between the interruption of light beams placed $125 \mathrm{~mm}$ apart. The gun pressure was set to obtain desired impact velocities between 10 and $100 \mathrm{~ms}^{-1}$.

Specimens in the form of $150 \mathrm{~mm}$ diameter discs with thicknesses in the range $3 \mathrm{~mm}-12 \mathrm{~mm}$ are held in a "Perspex" holder. This arrangement clamps the plates on a circular contact radius of $65 \mathrm{~mm}$ and allows the plate to bend under impact. In order to determine threshold velocities for damage to a single test plate the gun was aligned so that the point of impact was $40 \mathrm{~mm}$ radial distance of the centre. Tests were then undertaken an incremental impact velocities at up to twelve different locations by simply rotating the Perspex holder in the solid steel backing plate. The threshold velocity was taken as the minimum velocity required to cause damage to the plate specimen. The impact sites were examined visually and photographed using a low power stereo optical and scanning electron microscope. The impact damage varied as a function of velocity of impact above the threshold value.

For this initial study, simple laminates with polyvinyl chloride $0,2 \mathrm{~mm}$ thick layers on either or both faces of $3 \mathrm{~mm}$ annealed float glass and chemically strengthened $3 \mathrm{~mm}$ plates were tested. Laminates consisting of polyvinyl butyral or acrylic layers between $3.0 \mathrm{~mm}, 2,1 \mathrm{~mm}$ and $0,7 \mathrm{~mm}$ glass plates were also tested.

\section{Results}

The laminates tested which consisted of two glass plates of thicknesses varying from $0.7 \mathrm{~mm}$ to $3.0 \mathrm{~mm}$ interfaced by a water film of negligible thickness or a $0.7 \mathrm{~mm}$ layer of polyvinyl butyral or acrylic performed worse than the $3.0 \mathrm{~mm}$ monolithic specimen of annealed float glass. The threshold velocities for fracture are lower than that for a monolithic $3 \mathrm{~mm}$ annealed plate of float glass. These disappointing performances arise either from the fact that the total laminate thickness is greater than $3.0 \mathrm{~mm}$ and hence, Hertzian cracking of the front surface is more probable on the rigid specimen or that the total thickness is less than $3,0 \mathrm{~mm}$ and the resultant bending promotes cracking from the rear side. Typical failure modes are shown in fig. 1. Very significant improvements in the threshold velocities for $3.0 \mathrm{~mm}$ thick annealed float and chemically strengthened plates are obtained when a $0.2 \mathrm{~mm}$ thick layer of polyvinyl chloride is adhered to the front surface. (fig. 2) A similar layer on the back surface is also beneficial. For example, threshold velocities of 41 and 57 metres $\mathrm{ms}^{-1}$ have been measured for annealed float glass $3.0 \mathrm{~mm}$ plates with film on the back and front surfaces respectively as compared with the value of $28 \mathrm{~ms}^{-1}$ for the as received annealed plate. The modes of failure for ail of the coated plates is in intensive star cracking from the back side of the glass due to bending stresses created by the impact. The plastic film on the front surface de-localises the contact stress and the rate sensitive strength of the film on either surface opposes the local bending of the plate in response to the impact. The photograph of fig. 3 show the impact region on a $3.0 \mathrm{~mm}$ thick chemically strengthened plate with an adhesive film on the front surface. The glass is not damaged but the PVC film has sheared and fractured in the central zone under the imposed bi-axial stress.

The photographs of fig. 4 show the damage to the $3.0 \mathrm{~mm}$ thick chemically strengthened glass with PVC film on both surfaces when impacted at the velocity in excess of $95 \mathrm{~ms}^{-1}$. A crushed Hertzian cone was formed on the front surface whilst extensive star cracking occurred at the rear surface. 


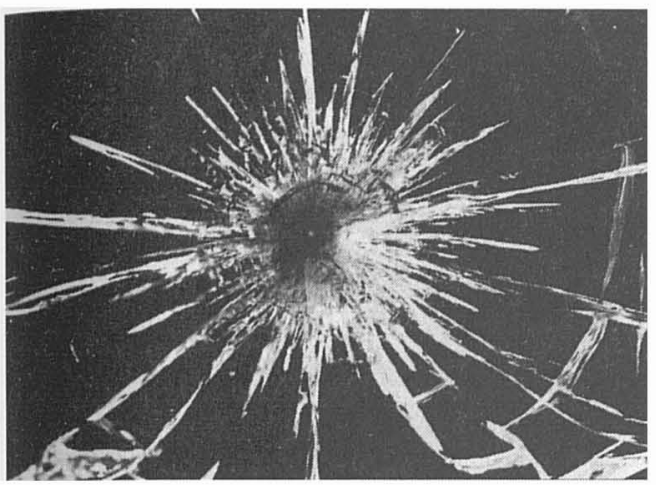

$\mathrm{X} 20$

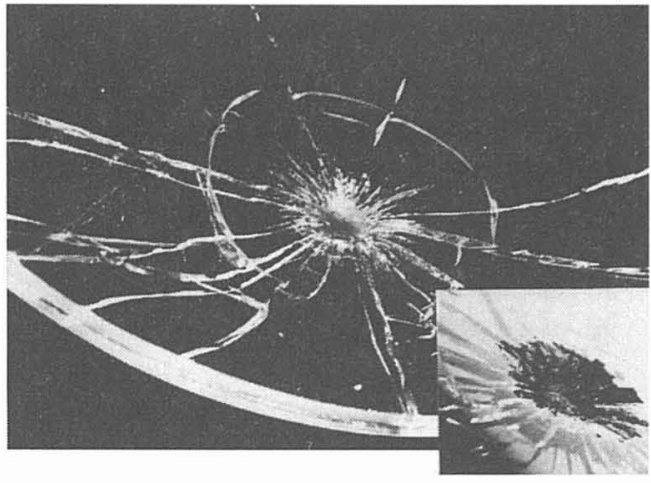

$\mathrm{X} 10$

fig. 1 A laminate consisting of a 2,1 mm front plate and 0,7mm PVB interlayer and a 2,5mm back plate after impact with a $5 \mathrm{~mm}$ dia. steel ball travelling at $61,9 \mathrm{~ms}^{-1}$. Both plates show cone and star cracking. Leftside photograph shows front face damage and the rightside photographs show star cracking and cone projection

$3 \mathrm{~mm}$ Plates with 200um Achesive Sheet

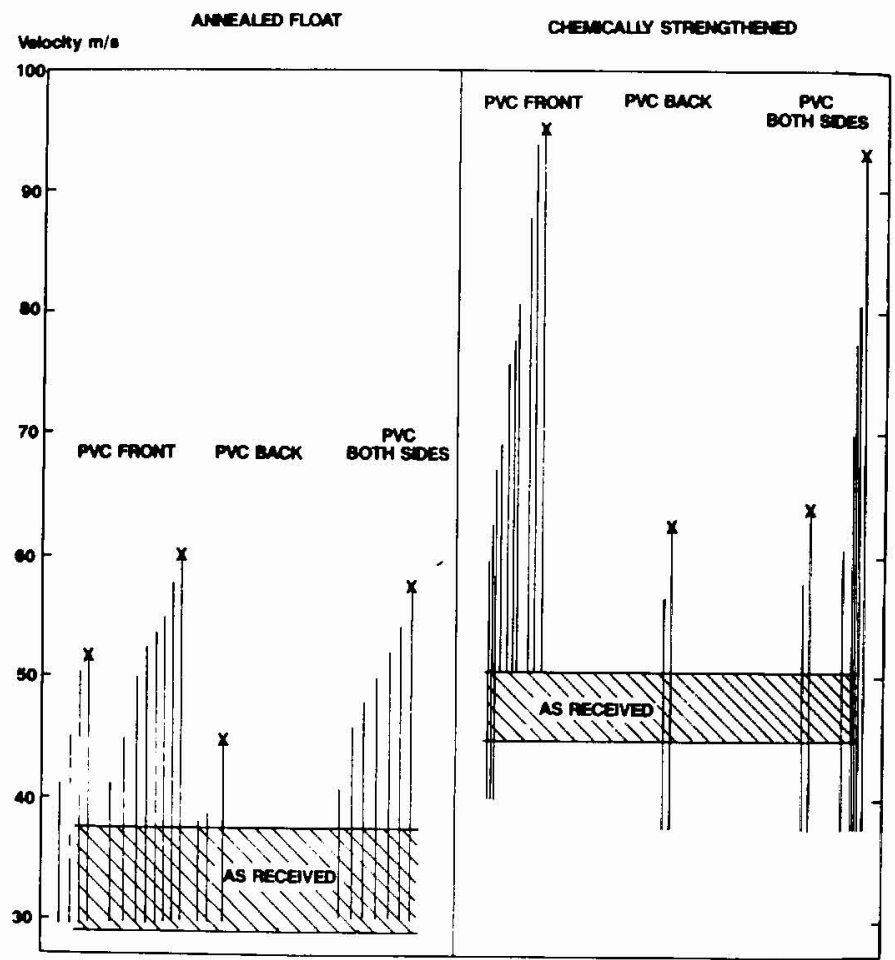

fig. 2 The impact performance of $3 \mathrm{~mm}$ plates with a plastic film on either the front, the back or both sides. The critical velocity for fracture is marked with an $\mathrm{x}$. Significant improvement over the as received plates is indicated. 


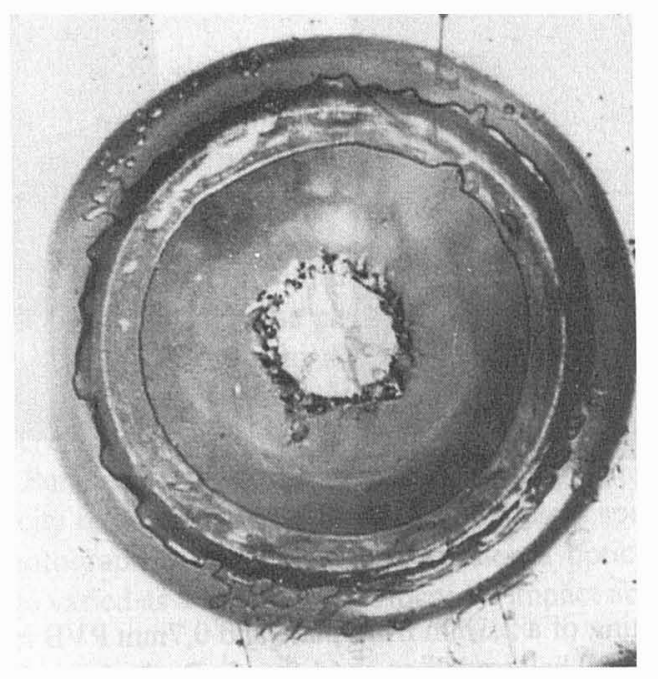

$\mathrm{X} 100$

fig. 3 Photograph of the damage to the plastic film at the point of impact. The film has sheared laterally and perforated in the centre.
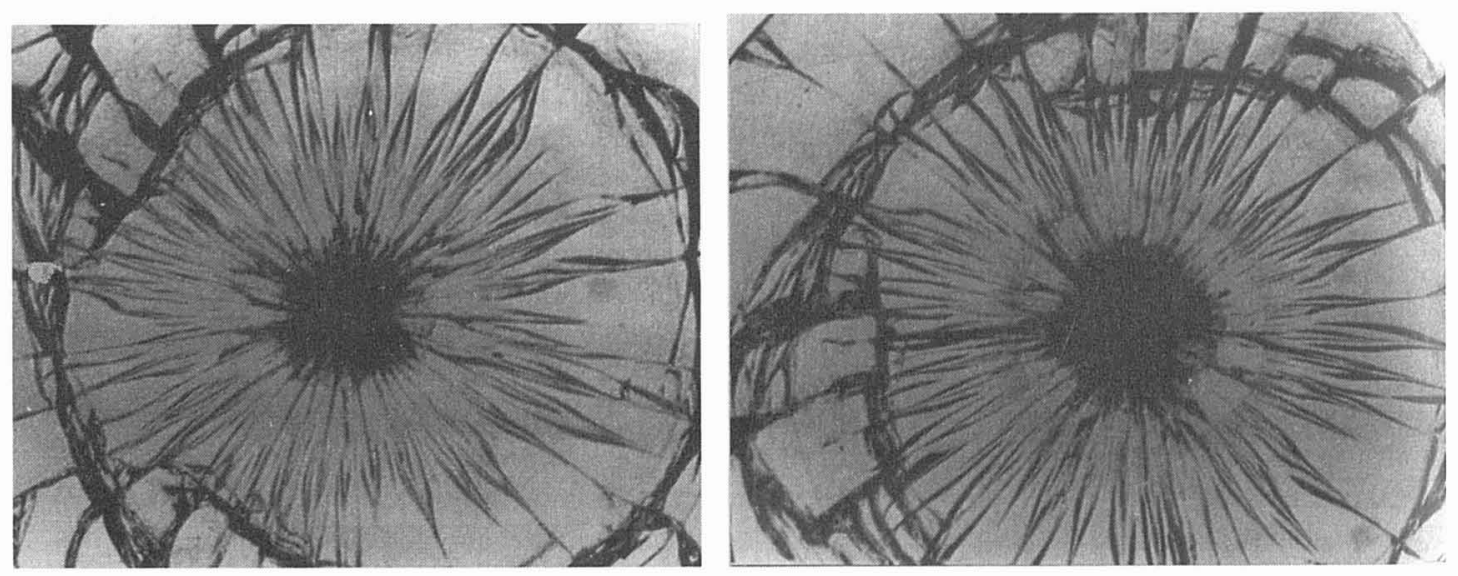

fig. 4 The damage produced in a $3 \mathrm{~mm}$ thick chemically strengthened glass plate with $0,2 \mathrm{~mm}$ thick polymer film on both surfaces by an impact at $94 \mathrm{~ms}^{-1}$. A crushed cone was formed on the front surface (lefthand photograph) whilst extensive star cracking occurred on the rear surface. (righthand photograph) 


\section{Discussion}

The design of a laminate screen for a specific application should incorporate all four factors identified in the experimental work by which the possibility of fracture of a single plate can be reduced. Namely, (i) the astute choice of plate thickness (ii) the reduction of surface defects by prior etching (iii) the provision of a surface compression layer to inhibit the propogation of surface defects (iv) the provision of 'soft ' coatings in order to diminish and de-localise the contact stresses. Factors (ii) and (iii) are well established in the literature and have been verified in the present series of experiments. A consideration of soft coatings was made by Mathewson[4] and experiments were undertaken by Chaudhri and Smith[5] and Chaudhri and Chen Ruiyi.[6]

The optimisation of glass thickness was discussed by Glathart and Preston ${ }^{[7]}$ who considered the competition between the contact streeses on the front surface and the bending stresses on the rear surface for a beam or lath of glass impacted by a steel ball. They showed that the contact stress increases with thickness to the power $3 / 2$, whilst the bending stress decreases with thickness to the power -2 . Thus in principle, one can calculate the optimum plate thickness to resist a given impact situation. However, the behaviour of a glass plate will be influenced by the size and spatial density of the surface flaws which experienced the stress fields on the front and rear surfaces. The Hertzian stresses on the front surfaces are extremely localised, whereas the bending stress on the rear surface is more dispersed. Thus, it would be anticipated that fracture by bending is more likely for a given impact condition. In the present experiments for velocities between 20 and $100 \mathrm{~ms}^{-1}$ the observed critical thickness is close to $3 \mathrm{~mm}$. Thinner plates generally break in a bending mode whilst thicker plates are damaged by the contact stress. Thus, in the design of a simple laminate consisting of a front glass plate, a polymer interlayer and a rear glass plate for velocities up to $100 \mathrm{~ms}^{-1}$, the front plate should be approximately $3 \mathrm{~mm}$ thick and be allowed to bend when impacted. The elastic properties and thickness of the polymer interlayer should be chosen so that the optimum degree of bending is allowed. The rear plate should provide the elastic rigidity which prevents the bending of the total laminate. Thus, the rear plate can be considerably thicker than the front plate and in this way, the probability of fracture by bending of the complete laminate would be decreased.

The experimental work confirms that both front and rear glass plates of the laminate should receive prior etching and chemical strengthening treatments which will reduce the flaw density and the probability of their propogation. In addition, both plates should be coated with a thin layer of soft polymeric material. This will have a significant effect on the possibility of fracture of the front surfaces of both glass plates by the imposed contact stresses.

\section{Conclusions}

Experimental work has verified the importance of plate thickness, surface treatments and surface coatings on the integrity of glass plates when subjected to projectile impact. On the basis of these findings, an optimal laminate design can be proposed for given impact conditions which should resist both fracture by contact stresses and bending stresses. 
References

[1] Ball A., McKenzie H.W., "On the Low Velocity Impact Behaviour of Glass Plates" Journal De Physique IV 4 (1994), pp 783-788

[2] Ball A., "On the Bifurcation of Cone Creacks in Glass Plates" Philosophical Magazine A 73, No. 4 (1996), pp 1093-1 103

[3] Ball A., "The Influence of Surface Treatments on the Hertzian Impact Damage of Glass" ECFI1 Mechanisms and Mechanics of Damage and Failure, 1, pp 639-644

[4] Matthewson M.J., "Theoretical Aspects of Thin Protective Coatings" Proceedings Fifth International Conference on Erosion by Solid and Liquid Impact, 73, 1979, pp 73/1-73/6

[5] Chaudhri M.M, Smith, Alan L.,"Damage to Polymer-Coated Glass Surfaces by Small Particle Impact"19th International Congress on High Speed Photography and Photonics 1358 (1990) pp 683689

[6] Chaudhri MM, Chen, Ruiyi., "Studies of the Indentation-Induced Debonding of Epoxy Coatings on Glass Substrates" Proceedings of Japan International Tribology Conference Nagoya (1990)

[7] Glathart J.L., Preston F.W., "Glass Technology" 9 (1968) No. 4, pp 89-100 